Universidad de Lima

Facultad de Comunicación

Carrera de Comunicación

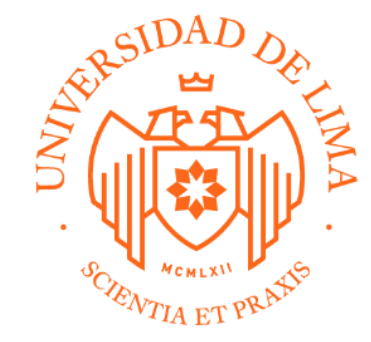

\title{
Estrategia comunicacional para la prevención de escalamiento del conflicto del proyecto "Tía María"
}

\author{
Trabajo de Suficiencia Profesional para optar el Título Profesional de \\ Licenciado en Comunicación
}

Diana Elizabeth Montoya Lloclla

Código 19930534

\author{
Asesor \\ Eduardo Lavado
}

Lima - Perú

13 Mayo, 2019 
Estrategia comunicacional para la prevención de escalamiento del conflicto del proyecto "Tía María" 


\section{ÍNDICE}

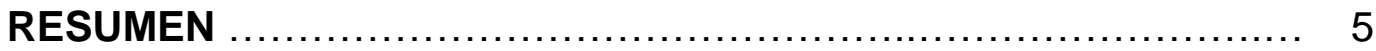

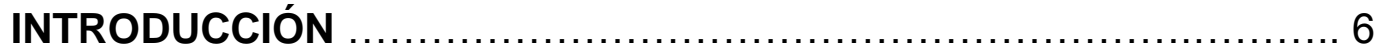

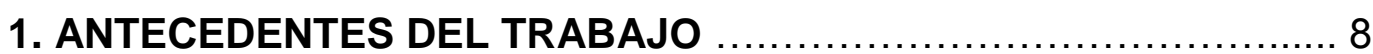

1.1 Conflictos Sociales en el Perú..................................... 8

1.1.1 Tipos de Conflictos......................................... 8

1.1.2 Actores Sociales........................................... 10

1.1.3 Medios de Comunicación, información y difusión............. 11

1.1.4 Presencia del Estado- Poder Ejecutivo......................... 12

1.2 Caso: "El Baguazo - 2009 ...................................... 13

1.3 Caso: "Tía María" - 2015 ........................................ 15

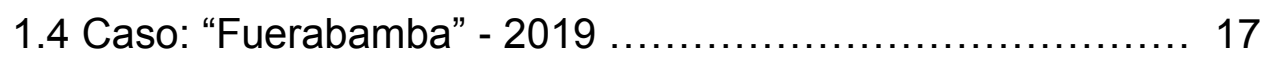

2. PROPUESTA DE COMUNICACIÓN .................................. 19

2.1. Situación actual del proyecto "Tía María........................ 19

2.2. Objetivo del Plan Comunicacional................................ 20

2.3 Público Objetivo .......................................... 21

2.4. Plan de Acción Comunicacional................................21

2.4.1 Elaboración de mapa de actores............................. 22

2.4.2 Identificación de Voceros Principales y Secundarios......... 22

2.4.3 Plan de media training para Voceros.......................... 23

2.4.4 Lineamientos de comunicación para voceros ................ 23

2.4.5 Talleres informativos a periodistas de Arequipa............. 24

2.4.6 Plan de medios locales y regional de Arequipa.............. 24

2.4.7 Desarrollo de Infografía de las acciones del Ejecutivo...... 25

2.4.8 Desarrollo de videos testimoniales.......................... 26

2.4.9 Aplicación Móvil del Mapa de Conflictos Sociales.......... 27

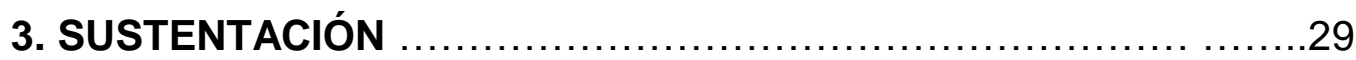

4. RECOMENDACIONES ….......................................... 30

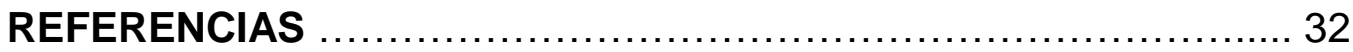

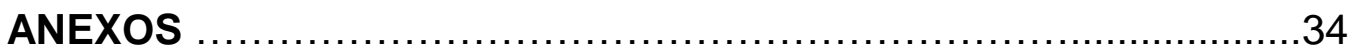




\section{RESUMEN}

La propuesta de la estrategia comunicacional que se ofrece al Ejecutivo, frente al conflicto social activo "Tía María", proyecto cuprífero de una inversión de US $\$ 1,400$ millones por parte de Southern, ubicado en el distrito de Cocachacra, provincia de Islay, Arequipa, tiene el objetivo principal de prevenir el escalamiento del conflicto de una fase temprana a una fase de crisis y así evitar la violencia o enfrentamientos entre la población y las autoridades, que pudiesen cobrar vidas, como los que sucedieron en la zona en el 2015.

Se ofrece una serie de acciones comunicacionales de varios sectores del Ejecutivo, en la zona de influencia del proyecto, principalmente a la población de Cocachacra y de la provincia de Islay, así como a los periodistas regionales, con el objetivo de brindar información transparente y oportuna sobre las acciones de los Ministerios de Agricultura (MINAGRI), del Ambiente (MINAM) y Energía y Minas (MEM), y así evitar vacíos de información o ausencia de las autoridades del Estado entre las comunidades. 


\section{INTRODUCCIÓN}

El Perú, tiene en la minería, la actividad económica más importante para el crecimiento y desarrollo nacional, al ser nuestro país, un importante productor y exportador de metales como el cobre, oro, zinc y estaño en el mundo.

Esta promesa de crecimiento económico por el boom minero, tiene un lado B de la historia, ya que varios de estos grandes proyectos mineros, afectan en mayor o menor grado, a las poblaciones que se encuentran en la zona de influencia, ya sea por no considerarlos actores importantes del mismo, por no cumplir los compromisos adquiridos al obtener la "licencia social" para ejecutar el proyecto, o por un manejo político de ciertas autoridades o intervenciones de organismos conllevan muchas veces a que se generen conflictos sociales socioambientales, que terminan escalando rápidamente a una etapa de crisis, enfrentando violentamente a la población con las autoridades o empresas mineras.

¿Qué es lo más importante, el desarrollo económico del país a través de estos grandes proyectos mineros o el bienestar de los peruanos, sobretodo, de aquellas poblaciones vulnerables? A lo largo de la historia de los conflictos sociales, la presencia del Estado ha sido casi ausente, en defensa de las poblaciones vulnerables frente a estos grandes proyectos, y que recién toma acción, cuando se generan estas crisis ya sea por un bloqueo de carreteras, la toma de instituciones o falta de respeto a las autoridades.

¿Es necesario llegar a este punto para llamar la atención del gobierno de turno para su intervención? El compromiso de todos los gobiernos, debiera ser el de garantizar, que la riqueza, que generen de estos proyectos mineros, impacten positivamente en el bienestar y desarrollo de las comunidades. El Estado, a través del Ejecutivo debería cumplir un rol permanente de informar a la población y a la prensa local-regional, verificando y garantizando que se cumplan los compromisos, y de observar y actuar, cuando estos no se cumplan.

Al tener una comunidad bien informada sobre las características, alcance del proyecto, los beneficios económicos que se obtendrán del canon o regalías, los proyectos de infraestructura que se desarrollaran, los compromisos adquiridos 
de acuerdo a un cronograma de trabajo, cómo proceder en caso sucedieran escenarios de desaprobación de la población, etc., tiene como resultado a una población empoderada con la información y activista en pro del bienestar y desarrollo de sus comunidades.

De esta forma, evitamos que aparezcan otros actores sociales ajenos o externos, que justamente ante la ausencia de información, aprovechan esa incertidumbre o muchas veces desconfianza, para marcar posiciones contrarias al desarrollo del proyecto o aprovechamiento de las comunidades, para obtener algún beneficio económico.

No se pueden desaparecer los problemas entre la población, la empresa extractiva y el Estado, pero sí se puede apostar por crear un sistema de comunicación que apoye en brindar la información a quienes lo demanden, por estar presentes en los espacios públicos, o plataformas informativas que demandan estas comunidades, y de brindar apoyo a las poblaciones más vulnerables, entendiendo su enfoque cultural y, así poder prevenir, el escalamiento de estos conflictos sociales, para evitar hechos lamentables. 


\section{ANTECEDENTES DEL TRABAJO}

\subsection{Conflictos Sociales}

El Perú tiene una larga historia de conflictos sociales y en los últimos 20 años, afronta unas decenas hasta casi más de una centena de conflictos sociales activos anuales. Los conflictos sociales deben ser entendidos como "un proceso complejo en el cual, sectores de la sociedad, el Estado y las empresas perciben que sus objetivos, intereses, valores o necesidades son contradictorios y esa contradicción puede derivar en violencia." (Defensoría del Pueblo, página web institucional).

La complejidad de los conflictos está determinada por el número de actores que intervienen, por la diversidad cultural, económica, social y política, además de las formas de violencia que se pueden presentar en ellos, la ausencia de un enfoque intercultural en las mesas de diálogo y finalmente, de la debilidad de las instituciones del Estado para atenderlos.

Según el último informe de la Adjuntía para la Prevención de Conflictos Sociales y la Gobernabilidad de la Defensoría del Pueblo ( $N^{\circ} 181$ - Marzo 2019), a la fecha, esta institución tiene registrados 183 conflictos sociales de los cuales 135 están activos y 48 latentes a nivel nacional.

\subsubsection{Tipos de Conflictos}

De acuerdo con la tipología de los conflictos sociales utilizados por la Defensoría del Pueblo - que ha sido tomado de los boletines informativos mensuales que emite - hay 10 tipos de acuerdo a la naturaleza del conflicto como los socio ambientales, demarcación territorial, laboral, comunal, electoral, cultivo ilegal de coca, de gestión del gobierno local, regional y nacional, entre otros. Los conflictos socio ambientales son los que más abundan en el país, esto por el control, uso y/o acceso al ambiente y los recursos naturales.

De acuerdo a la Defensoría del Pueblo, establece que son 5 fases que se dan en función al incremento o disminución de la violencia, y las posibilidades de diálogo y entendimiento. La primera la fase temprana, cuando los actores hacen 
pública la incompatibilidad de objetivos, medidas, posiciones, intereses, valores o necesidades existentes. La segunda, fase de escalamiento, cuando las relaciones de tensión entre las partes en el conflicto social y la intensidad de las acciones de violencia física directa aumentan. La tercera, fase de crisis, cuando expresan públicamente los reclamos a través de acciones de violencia contra las fuerzas del orden, contra otros agentes del Estado o contra particulares. La cuarta, fase de desescalamiento, cuando la intensidad de las acciones de violencia física directa disminuye, y las relaciones de tensión entre las partes en el conflicto social se pueden transformar en oportunidades para el diálogo. La quinta, fase de diálogo, cuando se desarrolla un proceso comunicacional en el que los actores intercambian información, argumentan, generan opciones, construyen acuerdos en un espacio ordenado, igualitario y sujeto a reglas.

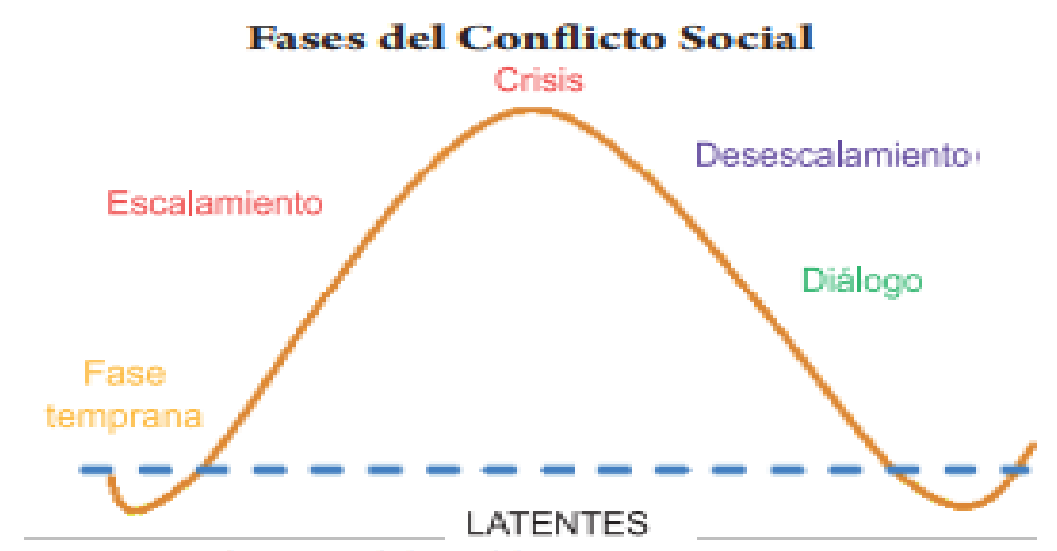

Fuente: Defensoría del Pueblo

La Secretaría de Gestión Social y Diálogo, a través de sus boletines informativos, en el marco de la gestión de prevención de situaciones de conflictos a nivel nacional, cuenta con un Sistema de Alerta Temprana, con el objetivo de gestionar la información de manera eficiente, para la elaboración e implementación de intervenciones políticas, estrategia y acciones para prevenir el escalamiento de conflictividad. Este sistema, se trabaja con los representantes de las oficinas de gestión social de los diferentes sectores del Ejecutivo y sus órganos adscritos. 


\subsubsection{Actores Sociales}

Un rol importante lo tienen los actores sociales que de acuerdo a su involucramiento, directo o indirecto podemos clasificarlos como actores principales, secundarios o terciarios. Entre ellos, podemos identificar a las comunidades, autoridades sub nacionales (gobernadores, alcaldes municipales o provinciales), instituciones, empresas, organizaciones de la sociedad civil o personas vinculadas indirectamente al conflicto que por sus características pueden tener incidencia en el curso del mismo.

Sobre estos actores sociales, se plantean propuestas de evaluación sobre la posición que tiene cada uno de ellos frente al problema por lo que se puede agrupar de acuerdo a la capacidad de influencia o poder de los actores versus nivel de impacto $u$ oposición de éstos.

\subsubsection{Medios de Comunicación, información y difusión}

Los medios de comunicación tradicionales que dominaron finales del siglo XX como la prensa escrita, radial o televisiva, siempre han tenido un impacto directo en la opinión pública (ya sea nacional, regional o distrital) con la difusión de información sobre el desarrollo de los conflictos sociales que escalaron o detonaron en crisis, por los enfrentamientos entre las partes y que éstas se volvieron de interés nacional por la aparición de hechos violentos.

La exposición de los actores y la construcción de un discurso mediático tiene un impacto en las audiencias, que contribuyen a crear percepciones de los roles de cada uno de los actores y de la realidad misma.

Estas percepciones son diferentes, considerando qué tipo de medio lo difunde considerando la ubicación y alcance del medio, el background de la audiencia, la "fuerza" del discurso mediático en el uso de calificativos, el abuso de imágenes de violencia y muerte, el número de veces que se repiten, quienes son los actores que aprovechan estos medios para marcar posiciones frente al conflicto, etc.

Asimismo, el tiempo de respuesta en la recepción de la información de acuerdo a la plataforma de información desde que se "dispara" el mensaje y que llega a una audiencia pasiva, sin feedback inmediato. 
Con el ingreso al siglo XXI, se unieron a estas plataformas informativas, las redes sociales, tales como facebook, twitter, que permiten una inmediatez en el envío de información desde diferentes actores y también corresponde una respuesta inmediata de los consumidores de la información, creando y aportando contenido sobre el mismo.

Alvin Toffler, en su libro "La Tercera Ola", acuña el término prosumer (productor y consumidor) en la cual "los consumidores, comienzan a ser creadores de contenido ocupando un nuevo papel cada mes más expansivo y estableciendo una nueva relación con la marca que no tiene porque ser beneficiosa siempre".

\subsubsection{Presencia del Estado- Poder Ejecutivo}

Frente al número de conflictos sociales que afronta el país, cabe reflexionar ¿cuál ha sido el rol del Estado desde la mirada del gobierno nacional, regional, local? ¿Qué tanto han hecho o dejado de hacer frente al conflicto con la población? Las comunidades hablan de una ausencia del Estado o principalmente del Ejecutivo que pueda apoyarlos frente a estas grandes empresas mineras que no cumplen sus compromisos. El centralismo se convierte en parte, en uno de los enemigos para resolver los problemas que ocurren fuera de la capital.

Autoridades subnacionales y poblaciones se acercan a la capital pidiendo audiencias en los Ministerios del Ejecutivo, buscando soluciones a sus problemas, demandando su presencia y apoyo a sus necesidades o hasta a veces carencias en sus lugares de orígen.

$Y$ desde Lima, donde se concentra poco más de la tercera parte de la población nacional, donde se ubican casi todas las instituciones del Estado, la aglomeración de las actividades económicas, del capital y de los trabajadores en determinados espacios geográficos, lo que lleva a la concentración del poder económico en algún lugar. (Efraín Gonzales de Olarte, 2017)

En el Perú, hay más de 1900 distritos en todo el país ¿se dan abasto para atender a todos? ¿se tienen claras las prioridades para la construcción de carreteras, escuelas, hospitales, agua y desagüe identificando a los distritos de pobreza y extrema pobreza? Tal vez se priorizan aquellas zonas, que donde se ubican estas operaciones mineras que dará un beneficio económico al país 
Y si es así ¿por qué el Estado no actúa inmediatamente en favor de esa población o comunidades en pro de su bienestar y desarrollo? ¿por qué reacciona cuando se tiene tomada una carretera o instituciones, o lo que es peor, cuándo afecta el PBI o crecimiento económico del país?

En el escenario de crisis de los conflictos sociales, ha sido testigo del desenvolvimiento y posiciones de Presidentes de Estado, Primeros Ministros y Ministros de Estado frente al problema. Lo que se logró en la primera reacción frente al conflicto, por nuestras autoridades, fue no tomar partido por parte de la población, acercarse a escucharla, entender sus necesidades, demandas y por qué no, de sus carencias. $Y$ todo queda registrado en sus declaraciones $u$ omisiones ante los medios de comunicación.

Las crisis del "Baguazo" en el 2009, "Tía María" 2015 y "Fuerabamba" 2019, todas de origen socio ambientales, reflejan cómo el Ejecutivo no tomó la prevención necesaria para atender y responder las demandas o necesidades de la población en la zona del conflicto. Trató de "trazar la cancha" o inclinar la balanza de manera negativa hacia las comunidades protestantes. Lo que es peor, cuando las autoridades tienen mirada "diferente" hacia la población del ande o de la selva, cuando no considera su diversidad cultural para comprender y llegar a ellos.

A continuación, haremos una evaluación de las 3 crisis de conflictos sociales mencionados anteriormente y analizaremos cuál fue el rol de los actores del Ejecutivo. 


\subsection{Caso: "El Baguazo" - 2009}

El 05 de Junio de 2009, durante el segundo gobierno de Alan García, se llevó a cabo "El Baguazo" el enfrentamiento entre la población indígena aguarunas y huambrishas, de la zona de Bagua, frente a la Policía Nacional del Perú, que tuvo un saldo de 33 personas fallecidas (23 policías y 10 nativos) y 1 desaparecido. Este es el conflicto social con mayor cantidad de muertos y heridos que se tiene registrado en nuestro país.

Un año atrás, en el 2008, las comunidades nativas de la región Amazonas, venían expresando su malestar frente a los decretos legislativos aprobados por el gobierno de turno, por el uso de tierras amazónicas que serían entregadas en concesiones a inversionistas y que se encargarían de explotar, los recursos naturales ubicados en el subsuelo.

La Asociación Interétnica de Desarrollo de la Selva Peruana (AIDESEP) también se opusieron a los decretos legislativos, reclamando al gobierno nacional, el atropello a los pueblos indígenas que viven dentro de la zonas que serían concesionadas, al no considerarlos para consultar.

Ya en Abril del 2009, AIDESEP inicia un paro amazónico, exigiendo la derogatoria de varios decretos que vulneran sus territorios. La huelga empieza a radicalizarse por toda la Amazonía y esto concluye, con el lamentable episodio del 05 de Junio. Este final lamentable, empuja al Congreso de la República derogar, los decretos cuestionados, con lo que puso fin a esta etapa del conflicto. Sin embargo, ¿cuál fue la posición del gobierno de turno, para buscar soluciones con las comunidades amazónicas? ¿cómo el gobierno pudo atender las demandas de información y respuesta de los medios de comunicación locales y regionales frente a lo que estaban reportando y observando el desenvolvimiento de los hechos?

Hasta el final del conflicto, ambos actores sociales fueron ignorados o no considerados importantes por el gobierno de turno. Esto llegó al punto más extremo, al darse la orden desde Lima que después de 56 días de bloqueo de carretera se proceda a retirar a los nativos de la carretera con las fuerzas policiales. 
Los actores políticos del Ejecutivo a lo largo del conflicto no lograron nada positivo con sus intervenciones y en algunos casos exarcebaron los ánimos de la población afectada. El Premier Yehude Simon, tratando que AIDESEP aceptara los decretos ley, la Ministra del Interior, Mercedes Cabanillas quien dio la orden a la Policía Nacional para el desalojo de los nativos y no aceptando su responsabilidad política frente a los hechos y el papel de la Ministra de Comercio Exterior, Mercedes Aráoz, principal impulsora del paquete de decretos que pretendían impulsar el desarrollo de la Amazonía y perfilar al Perú hacia el TLC con Estados Unidos.

Sin embargo, al escuchar las declaraciones del Presidente Alan García, jefe máximo del Estado peruano, al referirse así a las comunidades nativas, el mismo día del enfrentamiento con las fuerzas policiales, dio una muestra clara de que para su gobierno hay ciudadanos de primera y segunda clase: "Ya está bueno. Estas personas no tienen corona, no son ciudadanos de primera clase. 400 mil nativos no pueden decirnos a 28 millones de peruanos: tú no tienes derecho de venir por aquí".

(https:/larepublica.pe/politica/553595-conozca-las-patinadas-verbales-de-alangarcia - 5 de junio del 2009) y https://www.youtube.com/watch?v=rlj6XBa7pAE Con esto queda claro, como el Ejecutivo durante ese gobierno, no le interesaba llegar a ningún acuerdo con la población afectada, sino imponerse a la fuerza, deslindar responsabilidades políticas y penales por los muertos en el conflicto, persiguiendo a los líderes nativos y quitando licencia a un medio radial por alentar a la violencia. El interés principal, del gobierno de turno, fue el desarrollo económico del país a toda costa, a pesar de las comunidades nativas de nuestra amazonía. 


\subsection{Caso Tía María - (Marzo 2015)}

El 23 de marzo del 2015, se dio inicio al paro indefinido contra el proyecto cuprífero "Tía María", que incluye en su área de influencia, los distritos de Cocachacra, Mejía y Dean Valdivia, de la provincia arequipeña de Islay, en Arequipa. Fuerons sus autoridades ediles, quienes promovieron esta gran movilización contra el proyecto y la empresa encargada de la operación, desencadenando, unos de los conflictos más largos y tensos, que duró más de 60 días.

Las protestas alcanzaron picos de violencia que terminaron en enfrentamiento con la Policía Nacional del Perú, ocasionando poco más de una centena de heridos, decenas de detenidos y 4 personas fallecidas ( 3 civiles y 1 policía).

En el 2011, el Estudio de Impacto Ambiental (EIA) presentado por Southern, empresa minera a quien se le otorgó el proyecto, tuvo 136 observaciones por la United Nations Office for Projects Services (UNOPS), con lo cual, la población tuvo dudas respecto al proyecto y que éste fuera a contaminar su valle, afectando la producción agrícola de la zona. En medio de las protestas de ese año, 3 personas murieron por enfrentamientos con la Policía, con lo cual ese año, el proyecto quedó paralizado.

En Agosto del 2014, el Ministerio de Energía y Minas (MEM) aprueba el segundo Estudio de Impacto Ambiental (EIA) y Southern reinicia la promoción del proyecto entre la población de la zona de influencia, a la cual finalmente, no termina de convencer, por sus antecedentes de contaminación en otros proyectos mineros. Sin embargo, en Marzo 2015, en medio de un clima de tensión, se inician las protestas contra el proyecto "Tía María", en la cual entran a participar nuevos actores sociales.

En este caso particular, aparecen actores principales en este conflicto, como los alcaldes ediles de Cocachacra, Dean Valdivia, Punta de Bombón e Islay, la Junta de Usuarios del Valle del Tambo, el Frente de Defensa del Valle del Tambo, la gobernadora Yamila Osorio, el Presidente de Southern y Director de Relaciones Institucionales, Ministros del Ambiente, Energía y Minas, y del Interior, quienes tomaron su posición en contra o a favor del proyecto, apareciendo en los medios de prensa local, regional y nacional. 
Es así, que la gobernadora regional de Arequipa, Yamila Osorio, declaró en los medios, y subrayó la desconfianza de la población hacia Southern, por sus antecedentes en su desempeño ambiental y por los más de cien observaciones al primer estudio de impacto ambiental (EIA). La población está a favor de la minería responsable, sin embargo, los agricultores del Tambo, temen que partículas de polvo y mineral, terminen afectando la producción agrícola del valle, así como la falta de recurso hídrico en la zona, informó la gobernadora. (https://redaccion.lamula.pe/2015/04/07/yamila-osorio-sobre-tia-maria-novamos-a-permitir-ningun-proyecto-que-le-haga-dano-a-la-

\section{agricultura/jorgepaucar/ )}

Cabe mencionar, que en este conflicto, también se suman otros actores terciarios, ajenos a la zona del conflicto, y se trata de los representantes de Tierra y Libertad, en la figura de Marco Arana, quien tuvo un acercamiento con el Presidente de la Junta de Usuarios del valle del Tambo, y que inclusive logró movilizar gente desde Cajamarca hacia Islay.

¿Cuál fue la posición del Gobierno de Ollanta Humala frente al conflicto en Islay? ¿El Estado ha cumplido con sus obligaciones frente a la población? Antes de estallar la crisis en Islay, las oficinas de gestión social del MEM, MINAM intentaron aclarar y posicionar los resultados del EIA, pero ya había un rechazo de la población hacia el proyecto por la ejecución de la misma por la compañía Southern. Durante el estallido de la crisis, el presidente Ollanta Humala, fue cauto con sus declaraciones y fue su gobierno, quien más voceros del Ejecutivo envió a la zona para calmar los ánimos de la población. Sin embargo, no fue suficiente, para evitar los enfrentamientos que se desencadenaron en la zona de conflicto.

Al Presidente Humala, se le cuestionó su promesa como candidato a la presidencia versus su posición frente al proyecto, ya asumiendo el cargo de Presidente. Eso fue enrostrado por sus detractores, actores políticos de posiciones de izquierda que generó una desconfianza de la población que enardecida no querían escuchar más a los voceros del Ejecutivo.

(https://gestion.pe/peru/politica/ollanta-humala-tia-maria-creo-sea-convenienteislay-89716) 
Frente a esta situación, el presidente no le quedó más opción de declarar que era la población que otorgaría, la "licencia social" para la operación del proyecto a Southern. En consecuencia, el proyecto cuprífero "Tía María", nuevamente quedaba en espera y sin licencia de inicio de construcción, por la posición de la población. (http://www.actualidadambiental.pe/?p=30850)

\subsection{Caso Fuerabamba (Marzo 2019)}

En Enero del 2019, la comunidad campesina de Fuerabamba, representado por su presidente Gregorio Rojas solicitó una reunión con el Ministerio de Transportes y Comunicaciones (MTC) y otras instancias del Ejecutivo, así como al consorcio minero MMG Las Bambas para dar solución a las demandas de su comunidad en la provincia de Chumbivilcas en Cusco.

Concretamente, la comunidad campesina cuestiona la reclasificación de una vía, que pasa por el ex Fundo Yavi Yavi, denominada Ruta Nacional sin consulta alguna con la comunidad, así como la denuncia contra MMG Las Bambas quien construyó el tramo de la vía, por lo que exigen un pago de indemnización de daños y perjuicios.

EI MTC, quedó en dar respuesta previa convocatoria de todas las partes para determinar responsabilidad en la construcción de esa carretera, sin embargo, el tiempo pasó y la comunidad campesina no tenía respuestas.

El 04 de Febrero, la comunidad campesina bloquea la carretera que conforma el corredor minero de la ruta del traslado del mineral desde la minera misma en Apurímac que recorre la provincia de Cotabambas, cruza la provincia de Durante el mes de Marzo, Gregorio Rojas, empieza a presentarse en medios radiales y de televisión de la capital para dar conocimiento a la población sobre las demandas de su comunidad campesina, exponiendo el caso de la carretera.

En respuesta, el Estado empieza a difundir su posición frente al conflicto social, haciendo foco en la violación del libre tránsito en una vía nacional, por lo que solicitaron a la comunidad de Fuerabamba, que dejen de bloquear la carretera y permitan el libre tránsito. 
Asimismo, la Fiscalía sindican al presidente de Fuerabamba y a sus asesores legales, por cometer los delitos de crimen organizado y extorsión en el marco de las protestas contra la minera Las Bambas.

En paralelo, mientras suceden estas acciones, el MTC sigue sin dar una respuesta a la demanda de la comunidad, el 11 de Marzo, juramenta el nuevo gabinete de ministros, bajo la dirección de Salvador del Solar y es ratificado el Ministro Edgar Trujillo en el MTC.

El 19 de marzo, el Poder Judicial ordena la detención preliminar de los asesores legales de Fuerabamba por formar parte de una presunta organización criminal para exigir indemnizaciones millonarias a la minera Las Bambas.

Es aquí que aparecen dos actores importantes, los congresistas de Cusco, edgar Ochoa Pezo y de Apurímac, Richard Arce, quienes reclamaron al Ejecutivo que realice reuniones de diálogo con la comunidad.

Ya con un nuevo gabinete, el Premier del Solar y los ministros de Desarrollo e Inclusión Social (MIDIS), Salud (MINSA) y Transportes (MTC) forman parte de los voceros del Ejecutivo frente al conflicto y se realizará la primera reunión de diálogo con el Presidente de la comunidad campesina.

Hasta este punto, ¿qué es lo que hacía falta por parte del Ejecutivo en brindar la información y dar respuesta sea positiva o negativa de las demandas de la comunidad? ¿No es preferible darle prisa en resolverlas, o acercarse a la población para continuar con las reuniones, en vez de dilatarlas y que esto cree una percepción de que el Ejecutivo no tiene interés en darle apoyo a una comunidad campesina que se lo demanda?

El nuevo Premier Salvador del Solar, dirigió toda la búsqueda de diálogo, ya no solo con la comunidad de Fuerabamba sino con el resto de comunidades. Hizo uso del despliegue de un plan de medios, otorgando entrevistas en medios radiales y televisivos a nivel nacional, así como los medios digitales para posicionar el mensaje del Ejecutivo "Hemos buscado insistentemente mantener el diálogo con la comunidad de Fuerabamba". Inclusive en su presentación para el Congreso para la obtención del voto de confianza. 


\section{PROPUESTA DE COMUNICACIÓN}

Los conflictos son una oportunidad para que el Estado, a través del Ejecutivo genere espacios de acercamiento a la población, de escucharla, identificar sus necesidades, atender sus demandas rezagadas por muchos años, mejorar las relaciones con la población, tener presencia en el interior del país y así recuperar la confianza.

Pero también así de importante, es tener esa llegada con los medios localesregionales, así como las autoridades subnacionales para brindar oportunamente, con transparencia e identificando los mejores espacios o plataformas informativas para transmitir el mensaje del Ejecutivo respecto al proyecto desde sus diferentes frentes.

La falta de información, de uno de estos actores sociales y la suma de decisiones sorpresivas y no consultadas a la población e ignorar lo que opinan los actores sociales más importantes durante el conflicto, lo agudizan y contribuye al escalamiento a la crisis.

A continuación, se procede a describir la propuesta de una estrategia comunicacional, para el Poder Ejecutivo, sobre el proyecto "Tía María", con el objetivo de prevenir un escalamiento del conflicto, de una fase temprana a una fase crisis, ante la siguiente situación, que en Agosto pŕoximo, el Ministerio de Energía y Minas, otorgue la licencia a Southern para el inicio de construcción del proyecto cuprífero.

\subsection{Situación actual del proyecto "Tía María"}

A finales de Febrero del 2019, el ministro de Energía y Minas, Francisco Ismodes declaró a la prensa extranjera que el sector, podría estar otorgándole a Southern, finalmente la licencia de construcción para el proyecto Tía María de US $\$ 1,400$ millones antes de que termine su permiso ambiental en agosto próximo. "Es un proyecto que está priorizado por el Gobierno para que pueda ser implementado en el año 2019" (Agencia Reuters, 01 Marzo, 2019. https://ta.reuters.com/articulo/mineria-peru-idLTAL1N20N2E4).

Conociendo de antemano, los antecedentes ocurridos durante el 2015 y habiendo identificado en su momento los actores sociales que participaron en el 
desarrollo de los hechos de entonces, es importante señalar que este 2019 hubieron cambio de autoridades regionales, provinciales y distritales que tienen ya una posición clara frente al proyecto de acuerdo a sus intereses políticos.

En este caso, tenemos una figura política importante de la región Arequipa, que es el Gobernador de Arequipa, Elmer Cáceres, que hace 4 años cuando fue alcalde de Caylloma, lideró protestas contra el proyecto cuprífero. (https://peru21.pe/peru/gobernador-arequipa-enfrenta-ejecutivo-tia-maria-

\section{4)}

Asimismo, tenemos un nuevo gobierno, desde el 23 de Marzo del 2018, al frente del presidente Martín Vizcarra, a quien le toca la responsabilidad de cumplir el compromiso de su antecesor, Pedro Pablo Kuzcynski, quien el 20 de Enero del 2018, realizó una visita oficial al Valle de Tambo, en donde firmó un convenio entre el Gobierno Central, Gobierno Regional y Gobiernos locales, mediante el cual se financiaría y ejecutaría la represa e infraestructura agrícola que los pobladores venían demandando a MINAGRI, se realizaría el financiamiento y ejecución de los hospitales de Mollendo y Cocachacra por parte del MINSA y se ejecutaría el Plan Integral de Agua - Desagüe y tratamiento de aguas residuales en toda la provincia de Islay por parte del Ministerio de Vivienda, Construcción y Saneamiento. 2.2. Objetivo del Plan Comunicacional

Objetivo Principal

Prevenir el crecimiento del conflicto social de la fase temprana, en la que se encuentra actualmente, a una fase de escalamiento y/o generación de crisis, hacia la fase de escalamiento y crisis. Brindar información oportuna y transparente a la comunidad de Islay y Arequipa sobre la participación del Ejecutivo en garantizar su presencia en la zona hacia 3 grupos de actores sociales importantes: la población, los medios de prensa local-regional y autoridades subnacionales.

Se propone que los sectores como MINAGRI, MEM y MINAM aborden de forma integrada, coordinada y segmentada, toda información de su intervención en el desarrollo del proyecto con el fin de mantener informada a la población y a la 
prensa local y regional, de las acciones y decisiones del Gobierno en pro de la población.

\subsection{Públicos Objetivos}

Los grupos o actores sociales más importantes a quienes intervenir con este plan son la población de toda la provincia de Islay principalmente, a lla Junta de Usuarios del Valle del Tambo; a las autoridades subnacionales como los alcaldes ediles de Cocachacra, Punta del Bombón, Dean Valdivia, Islay y al Gobierno Regional de Arequipa; y finalmente a los medios de prensa localregional de Arequipa.

\subsection{Plan de Acción Comunicacional}

La propuesta implica en primera instancia, definir qué actores del Ejecutivo van a intervenir para el despliegue de la estrategia y ejecución de sus acciones. Se define a los Ministerio de Agricultura y Riego, Ministerio de Energía y Minas, Ministerio de Ambiente, Ministerio de Salud y Ministerio de Vivienda, Construcción y Saneamiento, y ViceMinisterio de Gobernanza Territorial.

MINAGRI, por el sector de la población que está teniendo mayor resistencia al desarrollo del proyecto y por la demanda de recursos hídricos en la zona por los agricultores.

MEM, para actualizar e informar a la población sobre el alcance del proyecto y lo que significa para el desarrollo económico de la zona de influencia y de la región misma.

MINAM, para actualizar e informar a la población sobre el status del Estudio de Impacto Ambiental, cómo fue el proceso y cómo la participación ciudadana fue importante para el conocimiento del mismo, así como para resolver las dudas de la población y escuchar sus opiniones.

MVCS, para brindar información en qué consiste el Plan Integral de Agua y Desagüe, así como el tratamiento de aguas residuales en toda la provincia de Islay que se prometió en el gobierno anterior.

MINSA, para brindar información de la ejecución de los hospitales de Mollendo y Cocachacra, cronograma de operación, número de pobladores que podrán atenderse, costo de financiamiento, servicios médicos que podrán recibir, fecha de inauguración, etc. 


\subsubsection{Elaboración de mapa de actores}

Como ya lo mencionamos en líneas arriba sobre el público objetivo nuestro plan, corresponde también mapear que otros actores intervienen en esta fase temprana del conflicto y tenerlos identificados.

\begin{tabular}{|l|l|}
\hline $\begin{array}{l}\text { Actores Principales } \\
\text { Participan directamente en el conflicto }\end{array}$ & $\begin{array}{l}\text { Actores Secundarios } \\
\text { Apoyan a alguna de las partes enfrentadas }\end{array}$ \\
\hline $\begin{array}{l}\text { Población de la provincia de Islay } \\
\text { Alcaldes de la Provincia de Islay } \\
\text { Gobernador Regional } \\
\text { Southern Cooper }\end{array}$ & $\begin{array}{l}\text { Medios de comunicación local y } \\
\text { regional. } \\
\text { Poder Ejecutivo (MINAGRI, MEM, } \\
\text { MINAM,) }\end{array}$ \\
\hline
\end{tabular}

\subsubsection{Identificación de Voceros Principales y Secundarios}

Dado que el público objetivo primario, que se ve afectada directamente por la operación del proyecto minero, son los agricultores del Tambo, se asignaría al titular del sector de Agricultura y Riego, quien dirija la vocería principal, ya que los usuarios del Valle del Tambo (agricultores) son los que tienen mayor resistencia al desarrollo del proyecto, por temor a que su agricultura, la producción de sus cultivos se vea afectada, así como la falta de recurso hídrico por el proyecto.

Los demás titulares como Energía y Minas, Ambiente como voceros secundarios vinculados a los temas de su sector que demande en la zona y sobre el proyecto.

\subsubsection{Plan de media training para Voceros}

Se propone desarrollar un cronograma de trabajo de media training, adhoc para el tema de Tía María, con los 3 voceros de MINAGRI, MEM y MINAM para prepararlos para lograr transmitir y colocar los mensajes claves sobre las acciones de su sector y del gobierno a la población local y regional.

Es importante destacar que para este training, es significativo que se prepare a los voceros de cómo abordar la prensa local y regional, considerando que su 
forma o estilo de comunicar es diferente a la que están acostumbrados en la prensa nacional.

Finalmente, tener conocimiento de las características sociales, personalidad del pueblo arequipeño, que muestra orgullo por su actividad agropecuaria, en la agricultura de sus valles con la producción de arroz, papa, ajo, olivo, maíz, frijol, además en la actividad pecuaria con la producción de leche fresca, carne de vacuno y aves y producción de huevos. Y que también son conscientes de la riqueza de sus suelos, para la instalación de operaciones mineras, para la extracción del cobre, principal mineral de exportación del país. (http://www.bcrp.gob.pe/docs/Sucursales/Arequipa/Arequipa-

\section{Caracterizacion.pdf)}

2.4.4 Lineamientos de comunicación para voceros

Se propone desarrollar lineamientos de comunicación para que los voceros puedan incorporarlos y transmitirlos, en todos los espacios en los que se les convoque para hablar sobre el tema.

\begin{tabular}{|l|l|}
\hline Tema & Mensaje \\
\hline $\begin{array}{l}\text { El gobierno garantiza su presencia } \\
\text { en la zona antes, durante y post } \\
\text { desarrollo del proyecto. }\end{array}$ & $\begin{array}{l}\text { "La participación ciudadana es clave para la } \\
\text { recuperación de la confianza del proyecto, por } \\
\text { eso el Ejecutivo brindará de forma inmediata, } \\
\text { transparente y oportuna la información que } \\
\text { requiera en cada uno de los procesos." }\end{array}$ \\
\hline $\begin{array}{l}\text { El Estudio de Impacto Ambiental } \\
\text { (ElA) cumplió con levantar todas las }\end{array}$ & $\begin{array}{l}\text { "El Servicio Nacional de Certificación Ambiental } \\
\text { observaciones }\end{array}$ \\
$\begin{array}{l}\text { Impacto Ambiental cumplen con todos los } \\
\text { aspectos normados y que éstos han sido } \\
\text { socializados, discutidos y revisados con la } \\
\text { población de la zona de influencia del } \\
\text { proyecto." }\end{array}$ \\
\hline
\end{tabular}




\subsubsection{Talleres informativos a periodistas de Arequipa}

Se propone convocar un taller informativo dirigido a los periodistas de la región con el fin de brindar información oficial y de primera mano de cómo el Ejecutivo está presente y vigilante de las necesidades de la población respecto al conocimiento del proyecto, su desarrollo e impacto.

Se obtendrá una base de datos de los periodistas de la prensa escrita, radial y televisión, así como invitar a importantes periodistas influenciadores en redes sociales a participar en el taller informativo.

Se requiere de la participación directa, de los Ministros de Agricultura, para abordar dos temas de interés de la población de Islay y de Arequipa, lo referido a agricultura y riego en la zona: "Modernización, buenas prácticas agrícolasinocuidad agraria en el Valle del Tambo" e "Infraestructura agraria y riego, tecnificación, seguridad y disponibilidad hídrica (Caso Represa Paltuture)".

En el caso de la Ministra del Ambiente, se propone la exposición sobre el "La importancia del Estudio de Impacto Ambiental (EIA) y la participación ciudadana en acceder a la información sobre el mismo". Este tema, en vista de resolver las consultas y dudas sobre el EIA vigente que vence en Agosto del 2019 y que pasaría con él en caso concluya la vigencia del mismo. Para esta exposición acompañará Servicio Nacional de Certificación Ambiental para las Inversiones Sostenibles (SENACE), organismo público técnico especializado, adscrito al Ministerio del Ambiente cuya tarea consiste en revisar y aprobar los Estudios de Impacto Ambiental detallados (EIA-d) de mayor envergadura de los proyectos de inversión pública, privada o de capital mixto.

En el caso del Ministro de Energía y Minas, se dará una actualización a los periodistas del "Alcance del proyecto cuprífero Tía María", en vista que el proyecto viene con años de atrasos desde el 2015 para el inicio del mismo.

Se adjunta en la sección de Anexos (Ver Anexo 1), el programa del taller informativo programado para el mes de Mayo.

2.4.6 Plan de medios locales y regional de Arequipa (prensa radial y escrita) Se propone planificar entrevistas en medios locales y regionales para que los voceros del gobierno puedan dar entrevistas con el objetivo de informar las 
acciones de su sector en la intervención y garantizar el cumplimiento de los compromisos del proyecto cuprífero, después del Taller Informativo.

Se propone de acuerdo al rating de audiencia que se registran en la región Arequipa del periodo 2018-02 (Compañía Peruana de Estudios de Mercados y Opinión Pública S.A.C.) en los siguientes medios:

Radios Locales y Regionales : Emisora Exitosa (FM), RPP y Melodía Voceros: Ministro de Agricultura, Energía y Minas, Ambiente.

También se priorizan planificar entrevistas en los principales y con buena lectoría (según IPG Media Brands) de los siguientes diarios de la región:

Diarios Regionales: Correo, El Pueblo, La República y El Comercio

Se adjunta en la sección de Anexos (Ver Anexos 2 y 3), el rating de audiencia radial y el ranking de medios escritos de la región.

\subsubsection{Desarrollo de Infografía de las acciones del ejecutivo}

Se plantea planificar con los sectores de MINAGRI, MEM y MINAM, desarrollar infografías para informar a sus seguidores en las redes sociales sobre las actividades, talleres, audiencias de participación ciudadana, que organizan para brindar información sobre los proyectos y escuchar las opiniones o resolver consultas de la población.

Principalmente, al publicar estas infografías en las redes sociales como twitter y facebook de los tres sectores del Ejecutivo, éstos tienen un gran alcance en sus seguidores como se describe a continuación:

\begin{tabular}{|l|l|l|}
\hline SECTOR & FACEBOOK & TWITTER \\
\hline MINAGRI & 238,000 & 315,000 \\
\hline MEM & 217,304 & 116,000 \\
\hline MINAM & 508,371 & 236,000 \\
\hline
\end{tabular}

Los temas que se proponen para estas infografías son:

MINAGRI: Fortalecimiento de las capacidades de gestión en materia agraria en la zona de acuerdo a los productos que se cultivan en el Valle del Tambo MINAM: Cómo se da la participación ciudadana ante la presentación del Estudio de Impacto Ambiental (EIA). 
MEM: El impacto de desarrollo y económico del proyecto cuprífero para la región Arequipa.

Estas infografías cumplen el objetivo de brindar información didáctica, simple y clara, de lo que hace el sector en favor de la población, entorno al proyecto a desarrollarse en la zona de influencia.

Se recomienda etiquetar a los tweets de los medios de comunicación locales y regionales, así como de autoridades distritales y provincial para que les llegue una notificación de la información publicada.

Se alcanza una propuesta de 2 infografías para MEM y MINAM e incluye para SENACE, para la publicación en redes de Facebook y Twitter (Ver Anexos 4, 5, $6,7,8,9)$.

2.4.8 Desarrollo de videos testimoniales de los pobladores frente al proyecto.

Se propone desarrollar 3 videos testimoniales, de cada uno de los sectores priorizados, con el objetivo que a través del discurso del video, darle la voz a la población y que en su propio lenguaje y en su entorno de trabajo puedan explicar sobre los mecanismos de participación ciudadana que tiene el Ejecutivo para brindar información sobre el proyecto.

Por ejemplo, en el caso de MINAM, se plantea un video en cuyo story borard y guión, se propone que la población explique de qué se trata el Estudio de Impacto Ambiental (EIA) y cómo ellos, a través de su participación, asistiendo en talleres y audiencias, conocerán las características y el alcance del mismo y podrán manifestar sus preocupaciones y alcanzar sus opiniones.

Este video tendrá varios formatos, para que puedan adaptarse e implementarse en las diferentes plataformas de redes sociales, tales como Twitter, Facebook, Youtube, que tienen los Ministerios y Organismos Públicos Adscritos.

Se propone también que al publicarse se etiqueten a las autoridades regionales tales como el Gobierno Regional de Arequipa, Alcaldía de Islay, Cocachacra, Punta del Bombón, Dean Valdivia, quienes recibirán una notificación de la publicación del video y podrán revisar el contenido. Como es de interés de su comunidad, el community manager de estas redes sociales podrá darle un retweet, un like, un me gusta o un compartir, y así amplificar la difusión del video. 
Asimismo, se plantea coordinar la difusión de estos videos, con la oficina de comunicaciones del Banco de la Nación y poder programar la difusión del video en los circuitos cerrados de televisión de las Agencias del Banco de la Nación, para amplificar la difusión del mismo, entre los usuarios del servicio bancario, con foco en la Región Arequipa.

Se adjunta en el Anexo del guión y propuesta story board del video de MINAM. (Ver Anexo 10)

\subsubsection{Aplicación Móvil del Mapa de Conflictos Sociales}

Desarrollar una aplicación móvil - para usuarios Android e IOS- sobre un Mapa de Conflictos Sociales en el Perú, con el objetivo de brindar acceso a información pública a todos los ciudadanos y conozcan el detalle del desarrollo y solución. Conocer de qué naturaleza son, cuál es el origen, en qué fase se encuentran, cuáles son los problemas principales del conflicto y cuáles son las soluciones que se presentan por parte de las partes.

Como sabemos el número de conflictos sociales en nuestro país es muy alto y son muchas partes o sectores del Estado que participan en ella, por eso se propone hacer una co-creación y co-participación de esta aplicación, por una parte, con el Ejecutivo, bajo el Viceministerio de Gobernanza Territorial, donde se encuentra la Secretaría de Conflictos Sociales que se encarga del mapeo y seguimiento de los conflictos sociales y por otro lado con la Defensoría del Pueblo.

De esta forma, se podrá homologar términos, procesos o fases del Conflicto y retroalimentar información, previa validación de ambos.

Desde el front office, estas son las pantallas de la aplicación móvil a desarrollar desde la dirección www.conflictossocialesperu.gob.pe:

Home: Pantalla principal de la aplicación con el nombre de la Aplicación y se verá la url del mismo

Mapa del Perú: Se verá un gráfico interactivo del mapa del Perú donde el usuario podrá seleccionar cualquier región y tener una visión de cuántas y cuáles son los conflictos sociales activos. Se agrega un zoom para poder amplificar la imagen y ver más detalles de la data. 
Pantalla Regional: Serán visibles los puntos de los conflictos sociales de la región, y al seleccionar uno de ellos, se abrirá una ventana en la parte baja que dará la información del estadio del mismo.

Pantalla informativa:

Tipo de Conflicto Activo: Se definirá que tipo de conflicto es el que se tiene en la zona seleccionada, considerando la tipología que maneja la Defensoría del Pueblo y la Secretaría de Gestión Social de la PCM. Por ejemplo: Socio Ambiental. Se propone poner un ícono (i) de información, para que el usuario pueda conocer cuál es la definición que se pone cada uno de las tipologías.

Fase del Conflicto: Se publicará en qué fase del conflicto se encuentra que puede ser fase temprana, de escalamiento, de crisis, de desescalamiento y diálogo. También se propone poner un ícono (i) de información, para que el usuario pueda conocer la definición de cada fase.

Problema: Se publicará cuáles son los principales problemas que iniciaron el conflicto, quiénes son los actores sociales que participan de ellos y cuáles son las posiciones frente al problema. Documentado cronológicamente, conforme se va desarrollando el conflicto.

Solución: Se publicarán las propuestas y/o soluciones al conflicto por parte de cada una de las partes. Se podrán visualizar cronológicamente, las actas de reuniones en busca de solución, las actas de compromisos de las partes, las mesas de diálogo activadas, etc.

Medios de Comunicación: En las últimas 2 secciones, se creará un link para revisar la publicación de cómo han reportado el conflicto los medios de comunicación tradicionales e interactivos locales, regionales y nacionales.

En el back office de la aplicación, la aplicación tendrá una base de datos, a través del cual se podrá exportar información para los usuarios internos de la aplicación y crear modelos o perfiles de conflictos que puedan servir de data para ambas instituciones. 


\section{SUSTENTACIÓN}

Los conflictos sociales no se pueden evitar, forma parte del relacionamiento que se tiene entre personas o grupo de personas. Lo que podemos hacer ante estas situaciones, es poder prevenir el escalamiento hacia actos de violencia entre la población y autoridades y empresas

La propuesta de 9 acciones, planificadas por el Ejecutivo son de importancia para cubrir vacíos o falta de información por cualquier parte de los actores sociales principales o secundarios. Con esto, evitamos apariciones de mensajes errados, evitar hechos tergiversados, evidenciar que las autoridades están informadas del problema y se está tomando acción frente a ellas, buscar la colaboración de todos los actores para la resolución del conflicto.

En los 3 casos de conflictos revisados anteriormente, se ha detectado que recién durante el estallido de la crisis, es que recién el Ejecutivo hace una intervención directa cuando ya la población tiene una posición sobre la situación en desarrollo. Y esto complica aún más los resultados de las estrategias planteadas desde la Capital.

Una prensa local y regional bien gestionada posicionando un plan de medios de los principales voceros, hace que se pueda resolver dudas o consultas y hasta posicionar mensajes del Ejecutivo frente a la audiencia televisiva, radial, digital o los lectores de medios impresos.

Las redes sociales siempre serán la plataforma más rápida e inmediata para posicionar mensajes e información para su amplia audiencia digital. Tener preparadas infografías con detalles y características de lo importante que es para el Ejecutivo la participación ciudadana en la autorización social para el inicio de la misma o producir videos testimoniales que informen sobre los mismos, siendo los mismos pobladores en su propio lenguaje y modos de hablar, lo expliquen a sus pares.

Finalmente, las autoridades sub nacionales, responden también a intereses políticos, y con ellos hay otros espacios como los GORES o MUNI EJECUTIVOS para poder intervenir directamente con ellos. 


\section{RECOMENDACIONES}

Se plantean las siguientes recomendaciones de otras acciones que van más allá de un plan comunicacional y en la cual intervienen otras instituciones. Todas complementarias a la propuesta presentadas.

1. Crear sinergia de trabajo entre la Secretaría de Gestión Social y Diálogo (PCM), con la Adjuntía de Conflictos Sociales (Defensoría del Pueblo), articulando un sistema de comunicación para la prevención de escalamiento de conflictos sociales. Se recomienda, organizar reuniones de trabajo entre los comunicadores para alcanzar la propuesta del trabajo de comunicación hacia las comunidades y la prensa local-regional, para identificar los vacíos de información que requieren por parte del Estado, del Ejecutivo.

2. En los GORES y MUNI Ejecutivos que organiza la Secretaría de Descentralización de la PCM, se propone incluir en el programa, temas relacionados con los conflictos sociales activos, y cuáles son los procedimientos para la atención del Ejecutivo hacia las comunidades desde la Secretarías de Gestión Social y Diálogo de la PCM, así como de sus oficinas de Diálogo en los 19 ministerios. Esto dará mayor visibilidad del trabajo del Ejecutivo en estos temas frente a las nuevas autoridades sub nacionales.

3. El Ejecutivo, debe organizar talleres informativos a la prensa regional en las zonas de mayor incidencia, sobre la participación de algunos de los sectores en conflictos sociales activos, invitando también a otras instituciones como la Defensoría del Pueblo, Ministerio Público y Poder Judicial para brindar información de primera mano, de sus altas autoridades, de cuál es el proceder de cada una de sus instituciones.

4. Se puede elaborar una encuesta digital a los periodistas regionales, para identificar cuales son las necesidades o problemas más comunes para la cobertura informativa de los conflictos sociales. Esta encuesta debe ser segmentada de acuerdo al tipo de medio (TV, Radio, Escrito, Digital). 
5. Atender y mapear a la prensa regional, que solicita información de los sectores, y hacer seguimiento de la reproducción en sus medios informativos.

6. Priorizar el diálogo y la accesibilidad de la información con enfoque intercultural de la zona de influencia, permitiendo un intercambio abierto y respetuoso de opiniones entre la comunidad y las autoridades, en los espacios públicos como talleres o audiencias de participación ciudadana. 


\section{REFERENCIAS}

Actualidad Ambiental (2015) "Humala sobre Tía María: "Nosotros vamos a hacer lo que la población diga"

(http://www.actualidadambiental.pe/?p=30850)

Agencia Reuters. "Perú planea otorgar permiso clave a Southern Copper para retrasado proyecto de cobre"

(https://ta.reuters.com/articulo/mineria-peru-idLTAL1N20N2E4)

Arrunategui, Carolina (2010) "Ideología y prensa escrita en el Perú: el caso Bagua". Lexis Vol. XXXIV (2) 2010: 353-368

http://alertacontraelracismo.pe/sites/default/files/1544-5966-1-PB.pdf

Banco Central de REserva del Perú (2012) "Caracterización de la Región Arequipa"

(http://www.bcrp.gob.pe/docs/Sucursales/Arequipa/Arequipa-

\section{Caracterizacion.pdf)}

Defensoría del Pueblo (2019), Reporte Mensual de Conflictos Sociales N 181 Marzo 2019

(https://www.defensoria.gob.pe/documentos/reporte-mensual-de-conflictossociales-n-181/)

Defensoría del Pueblo (2018) "Los conflictos Socioambientales por actividades extractivas en el Perú"

(https://www.defensoria.gob.pe/wp-

content/uploads/2018/08/inf extraordinario 04 07.pdf)

Diario La República , Sección Política "Conozca las "patinadas" verbales de Alan García"

(https://larepublica.pe/politica/553595-conozca-las-patinadas-verbales-de-alangarcia)

Gonzales de Olarte, Efraín. (2017) "Concentración y centralización: Enemigos del desarrollo regional convergente y equitativo" Pontificia Universidad Católica. http://blog.pucp.edu.pe/blog/economiaperuana/2017/02/16/concentracion-ycentralizacion-en-el-peru-enemigos-del-desarrollo/

LaMula.pe (2015) "Yamila Osorio sobre Tía María: "No vamos a permitir ningún proyecto que le haga daño a la agricultura" 
(https://redaccion.lamula.pe/2015/04/07/yamila-osorio-sobre-tia-maria-no-

vamos-a-permitir-ningun-proyecto-que-le-haga-dano-a-la-

agricultura/jorgepaucar/)

Macassi, S. (2013). "Cobertura periodística de conflictos socioambientales".

Lima: Tarea Asociación Gráfica Educativa

MIRevista Cultural (2017) "El Centralismo y la Cultura Peruana"

(http://culturamir.com/el-centralismo-y-la-cultura-peruana/)

Ramón Ruffner, Jeri Gloria. (2012). "El papel del Estado frente a la Violencia en los Conflictos Sociales". Quipukamayok, Revista de la UNMSM

(http://revistasinvestigacion.unmsm.edu.pe/index.php/quipu/article/view/4003)

Secretaría de Gestión Social y Diálogo-Presidencia del Consejo de Ministros (2019), Boletín Willaqniki, Edición 03-2019

https://cdn.www.gob.pe/uploads/document/file/309836/WILLAQNIKI MAR2019. pdf

SENACE (2018), Guía de Participación Ciudadana con enfoque intercultural para la certificación ambiental

http://www.senace.gob.pe/wp-content/uploads/2018/12/PUBL-GUIA-DE-

PARTICIPACION-CIUDADANA-CON-ENFOQUE-INTERCULTURAL-PARA-

LA-CERTIFICACION-AMBIENTAL.pdf

Toffler, Alvin (1996), La creación de una nueva civilización : la política de la Tercera Ola. Barcelona : Plaza \& Janés, 1996

Willer, Hildegard (2015), Esferas públicas locales y conflictos sociales (1 ed.) Instituto de Estudios Peruanos - Perú 


\section{ANEXOS}

Anexo 1: Programa del Taller informativo para la prensa regional de Arequipa

\section{PROGRAMA MESA REGIONAL DE PRENSA AREQUIPA 2019}

\section{JUEVES 30 DE MAYO}

\section{Auditorio Municipalidad Provincial de Islay}

08:00 - 08:30 horas Ingreso, registro y acreditación de participantes. Los periodistas deben ingresar portando su DNI y Credencial de Prensa.

08:30 - 08.45 horas Palabras de bienvenida a cargo de la Secretaria de Comunicación Social Presidencia del Consejo de Ministros.

08:45 - 09:45 horas "Modernización, buenas prácticas agrícolas- inocuidad agraria en el Valle del Tambo" e "Infraestructura agraria y riego, tecnificación, seguridad y disponibilidad hídrica (Caso Represa Paltuture". Exposición a cargo de la ministra del Agricultura

Diálogo con preguntas y repuestas de periodistas.

10:00 - 11:00 horas "La importancia del Estudio de Impacto Ambiental (EIA) y la participación ciudadana en acceder a la información sobre el mismo". Exposición de la Ministra de Ambiente y Director Ejecutivo de SENACE

Diálogo con preguntas y repuestas de periodistas.

10:45 - 11:45 horas "Alcance del proyecto cuprífero Tía María". Exposición de la ministro de Energía y Minas.

Diálogo con preguntas y repuestas. 


\section{Anexo 2: Rating de Audiencia en radios de Arequipa}

\section{C.P.I. AUDIENCIA RADIAL DE EMISORAS EN PRINCIPALES CIUDADES}

Periodo 201802

Ciudad Arequipa

Lugar de audiencia Hogares/Fuera del Hogar

Bloques de dias Lunes a Sabado/Domingo

Horas $06-20 \mathrm{H}$

Nivel Alto - Medio/Bajo Superior - Bajo Inferior - Marginal

Grupo objetivo HM 17-25/HM 26-37/HM 38-50/HM 51+

Universo 668.70

\begin{tabular}{|c|c|c|c|c|c|}
\hline Rnk & Emisora & Rating & Miles & $A / B$ & $\mathrm{C} / \mathrm{D} / \mathrm{E}$ \\
\hline 1 & EXITOSA [FM] & 2.9 & 19.40 & 3.74 & 15.67 \\
\hline 2 & MELODIA [FM] & 1.8 & 12.37 & 2.66 & 9.72 \\
\hline 3 & R.P.P. [FM/AM] & 1.8 & 12.01 & 5.47 & 6.54 \\
\hline 4 & LA INOLVIDABLE [FM/AM] & 1.3 & 8.51 & 3.43 & 5.09 \\
\hline 5 & LA KARIBEÑA [FM] & 1.1 & 7.08 & 1.16 & 5.92 \\
\hline 6 & LA KALLE [FM] & 0.8 & 5.31 & 1.05 & 4.25 \\
\hline 7 & NUEVA Q FM [FM] & 0.7 & 5.00 & 0.93 & 4.07 \\
\hline 8 & PANAMERICANA [FM] & 0.6 & 3.81 & 1.53 & 2.28 \\
\hline 9 & OXIGENO [FM] & 0.5 & 3.62 & 1.72 & 1.89 \\
\hline 10 & FEUCIDAD [FM] & 0.5 & 3.57 & 1.18 & 2.39 \\
\hline 11 & MODA [FM] & 0.4 & 2.70 & 0.77 & 1.92 \\
\hline 12 & RITMO ROMANTICA [FM] & 0.4 & 2.65 & 0.94 & 1.71 \\
\hline 13 & SAN MARTIN [FM/AM] & 0.4 & 2.38 & 0.88 & 1.51 \\
\hline 14 & YARAV [FM/AM] & 0.3 & 1.95 & 0.38 & 1.57 \\
\hline 15 & MELODIA [AM] & 0.3 & 1.69 & 0.20 & 1.50 \\
\hline 16 & ONDA CERO [FM] & 0.2 & 1.67 & 0.30 & 1.37 \\
\hline 17 & STUDIO 92 [FM] & 0.2 & 1.48 & 0.39 & 1.08 \\
\hline 18 & LA ZONA [FM] & 0.2 & 1.44 & 0.23 & 1.22 \\
\hline 19 & CORAZON [FM] & 0.2 & 1.34 & 0.54 & 0.79 \\
\hline 20 & PLANETA [FM] & 0.1 & 0.78 & 0.31 & 0.47 \\
\hline 21 & CONTACTO SUR [FM/AM] & 0.1 & 0.34 & 0.00 & 0.34 \\
\hline 22 & OTRAS EMISORAS [FM] & 1.1 & 7.08 & 1.79 & 5.29 \\
\hline 23 & OTRAS EMISORAS [AM] & 0.6 & 3.94 & 0.81 & 3.13 \\
\hline 24 & NO RECUERDA & 0.5 & 3.59 & 0.87 & 2.72 \\
\hline
\end{tabular}

Fuente: Compañía Peruana de Estudios de Mercados y Opinión Pública S.A.C. 


\section{Anexo 3: Ranking de Diarios en Arequipa}

\section{RANKING DIARIOS AREQUIPA}

Base: Provincias

Período(s): Ciudades_2018

Target(s): Arequipa HM 20-75 Total

Cliente: IPG Mediabrands

\begin{tabular}{|c|c|c|}
\hline \multirow{2}{*}{ Diario } & \multicolumn{2}{|c|}{ Arequipa HM 20-75 Total } \\
\cline { 2 - 3 } & \multicolumn{2}{|c|}{ Ciudades_2018 } \\
\cline { 2 - 3 } & \multicolumn{2}{|c|}{ Lunes-Viernes } \\
\cline { 2 - 3 } & Alcance & Lectores \\
\hline EL POPULAR & 13.22 & 77,061 \\
\hline CORREO & 12.06 & 70,324 \\
\hline TROME & 8.29 & 48,353 \\
\hline DEPOR & 4.90 & 28,567 \\
\hline LÍBERO & 4.08 & 23,811 \\
\hline OJO & 3.25 & 18,942 \\
\hline LA REPÚBLCA & 2.81 & 16,384 \\
\hline EL PUEBLO & 2.52 & 14,673 \\
\hline PERÚ 21 & 2.44 & 14,197 \\
\hline EL COMERCIO & 1.24 & 7,203 \\
\hline
\end{tabular}

\begin{tabular}{|c|c|c|}
\hline \multirow{2}{*}{ Diario } & \multicolumn{2}{|c|}{ Arequipa HM 20-75 Total } \\
\cline { 2 - 3 } & \multicolumn{2}{|c|}{ Ciudades_2018 } \\
\cline { 2 - 3 } & Sábado-Domingo \\
\cline { 2 - 3 } & Alcance & Lectores \\
\hline EL POPULAR & 11.41 & 66,497 \\
\hline CORREO & 9.13 & 53,214 \\
\hline EL PUEBLO & 7.28 & 42,458 \\
\hline TROME & 5.71 & 33,313 \\
\hline DEPOR & 4.13 & 24,083 \\
\hline LA REPÚBLCA & 3.22 & 18,796 \\
\hline OJO & 2.41 & 14,053 \\
\hline EL COMERCIO & 2.38 & 13,848 \\
\hline ĹBERO & 2.36 & 13,762 \\
\hline PERÚ 21 & 1.90 & 11,050 \\
\hline
\end{tabular}


Anexo 4: Infografías para difusión en redes sociales para MEM (Facebook)

9.7. Ministerio de Energía y Minas del Perú

Ayer a las 10:53-9

Conoce más de las características del Proyecto Cuprífero de Tía María, con una inversión de US\$1,400 millones, que permitirá el crecimiento y desarrollo de la provincia de Islay, en Arequipa.

\section{PROYECTO MINERO TÍA MARÍA}

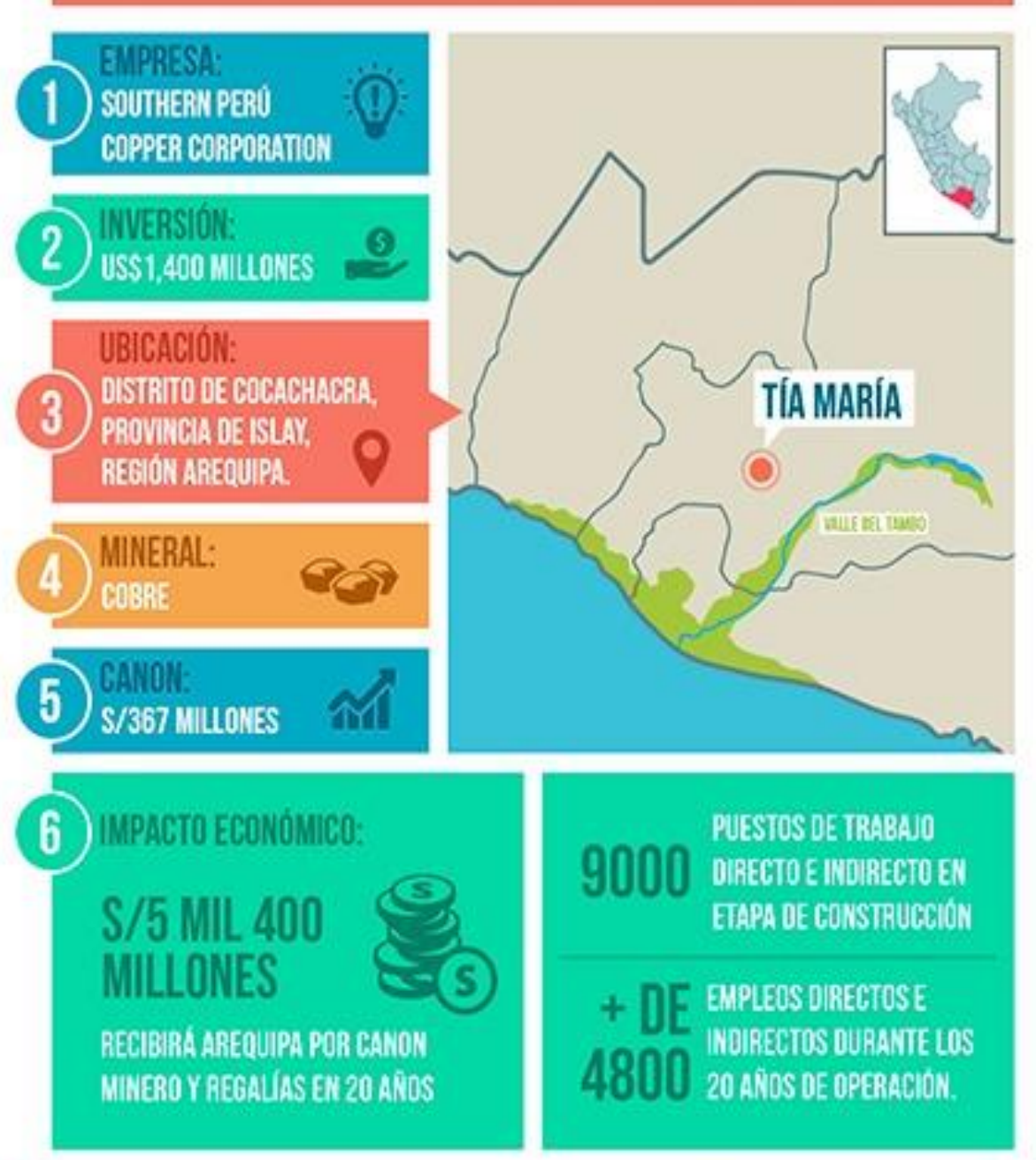

PERU Ministerls y Mins

El. Perú Primero 
Anexo 5: Infografías para difusión en redes sociales para MEM (Twitter)

MemPeru @MemPeru.9 mav.

Conoce más de las características del Proyecto Cuprífero de Tía María, con una inversión de US\$1,400 millones, que permitirá el crecimiento y desarrollo de la provincia de Islay, en Arequipa.

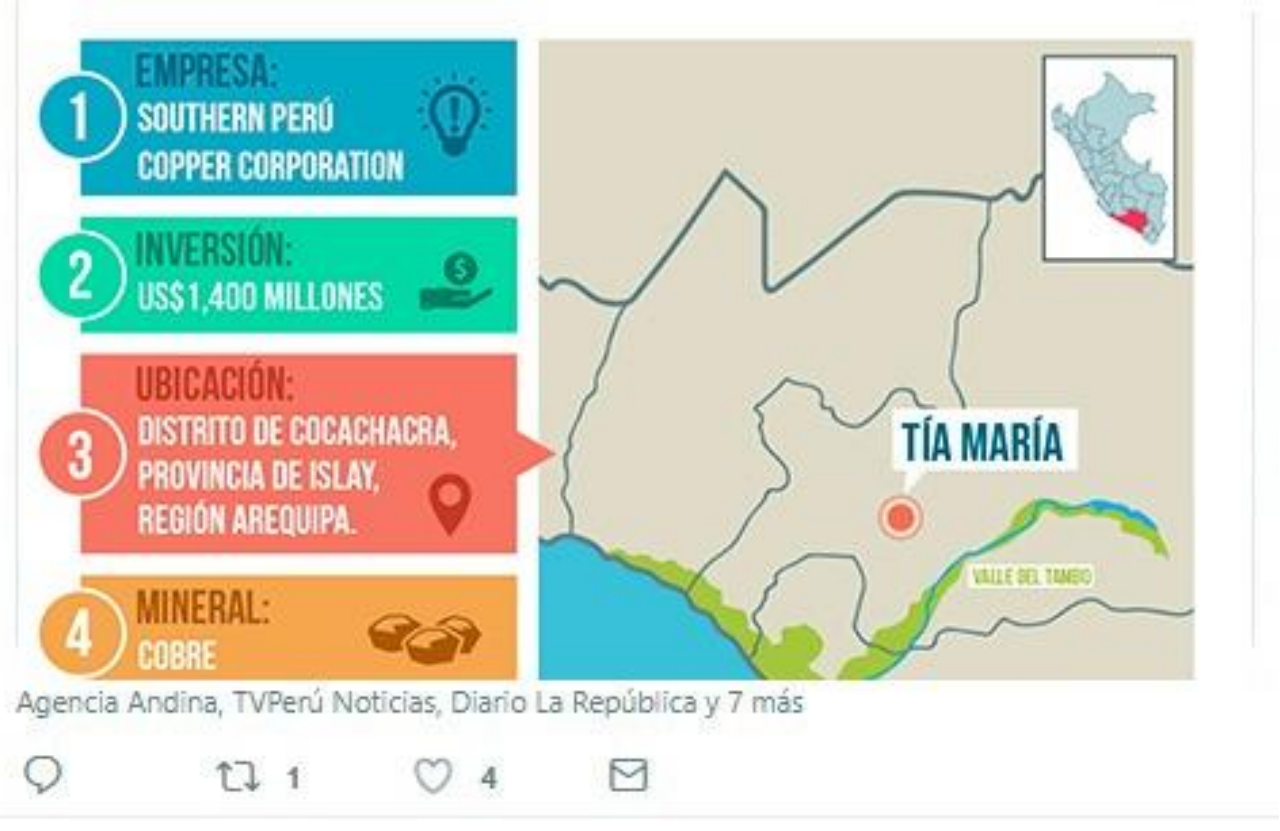


Anexo 6: Infografías para difusión en redes sociales para MINAM (Facebook)

2. Ministerio del Ambiente - Perú

7 horas 9

Ejerce tu derecho de participar en los talleres informativos y las audiencias que dan la oportunidad de absolver todas las inquietudes relacionadas con el Estudio de Impacto Ambiental (EIA-d). Recuerda, que con tu participación, no válidas el proyecto y no asumes ningún compromiso al firmar las actas.

\#SoySenaceSoylntegridad \#EIPerúPrimero
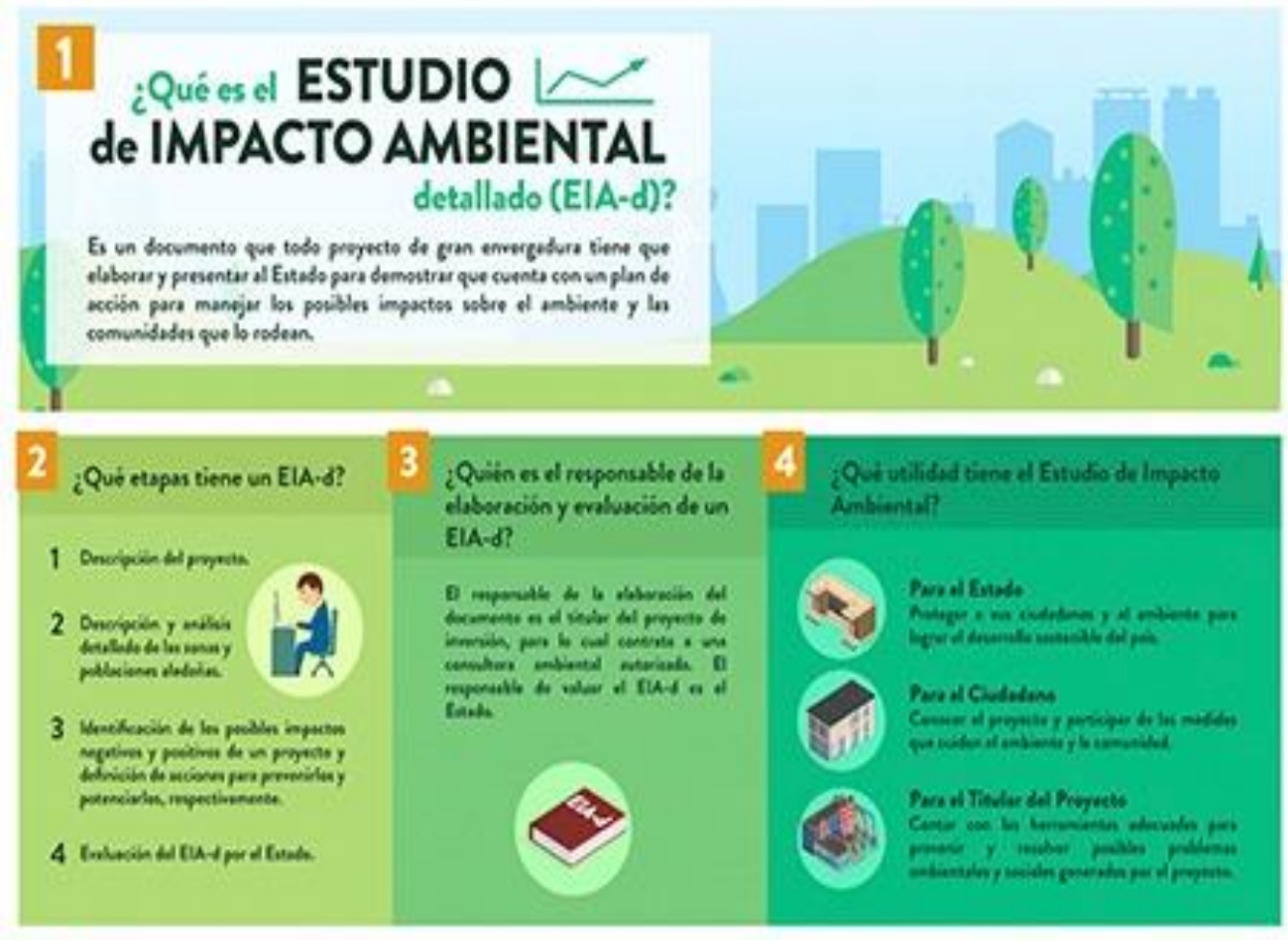
Anexo 7: Infografías para difusión en redes sociales para MINAM (Twitter)

\section{Ministerio del Ambiente@MinamPeru.6h}

Ejerce tu derecho de participar en los talleres informativos y las audiencias que dan la oportunidad de absolver todas las inquietudes relacionadas con el Estudio de Impacto Ambiental (EIA-d).

\#ElPerúPrimero

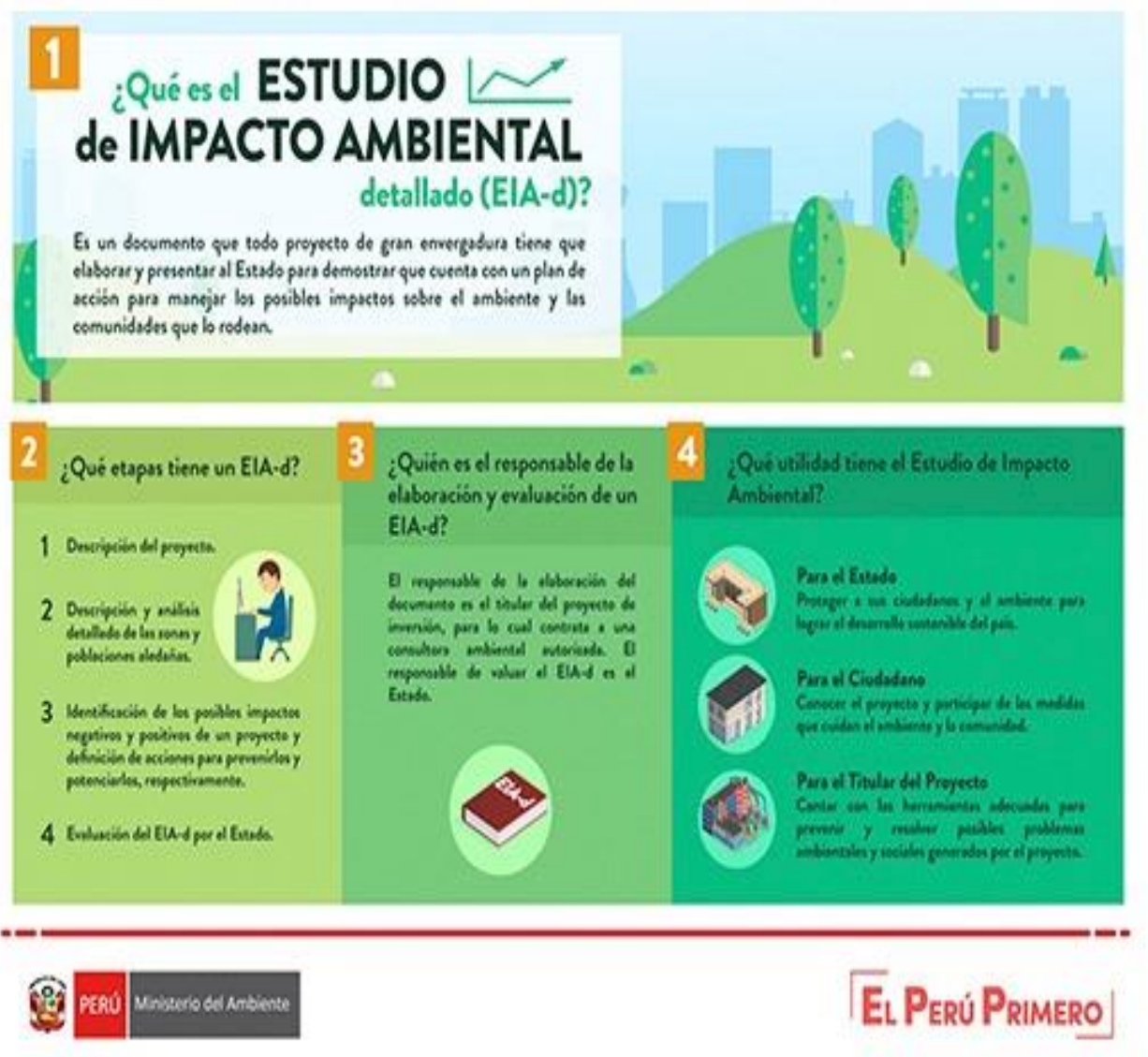




\title{
Anexo 8: Infografías para difusión en redes sociales para SENACE
}

\section{(Facebook)}

\author{
2. Senace Perú \\ senace 8 horas 9
}

Ejerce tu derecho de participar en los talleres informativos y las audiencias que dan la oportunidad de absolver todas las inquietudes relacionadas con el Estudio de Impacto Ambiental (EIA-d). Recuerda, que con tu participación, no válidas el proyecto y no asumes ningún compromiso al firmar las actas. \#SoySenaceSoylntegridad \#EIPerúPrimero

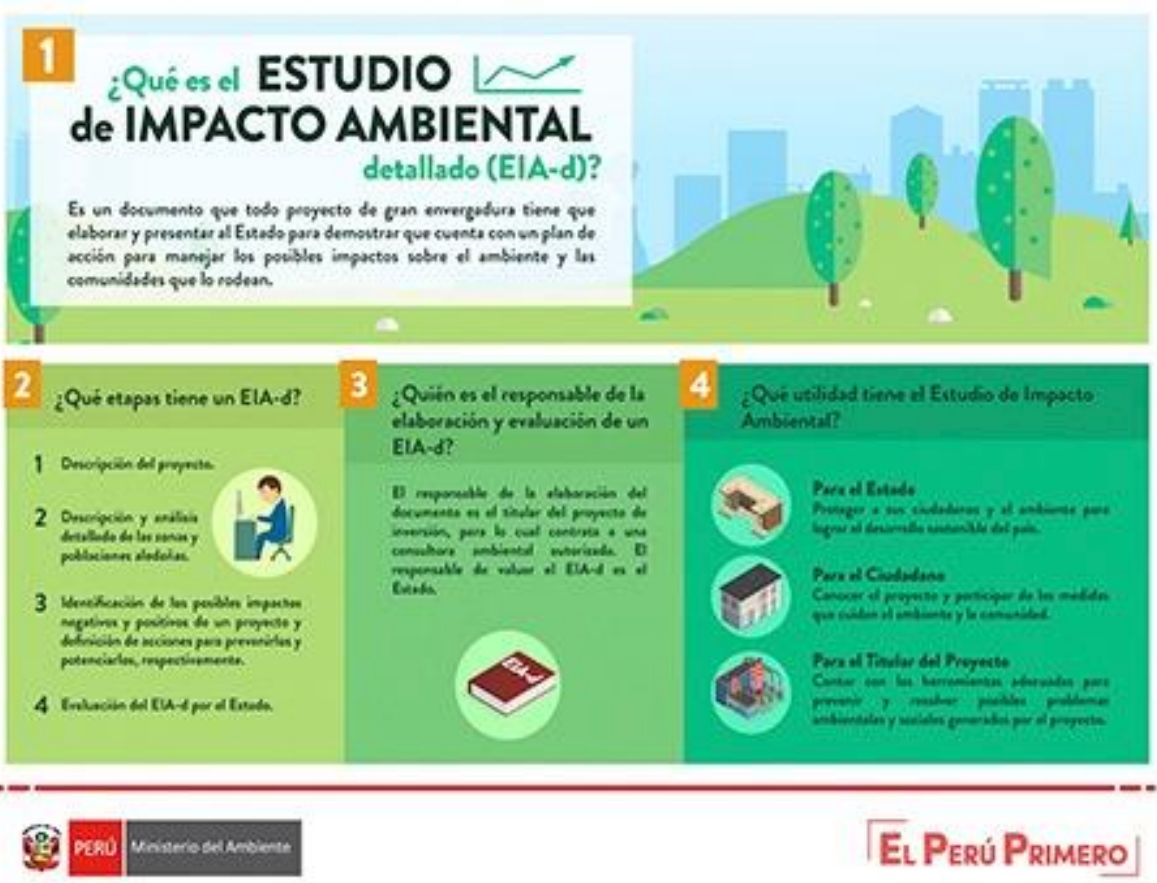




\section{Anexo 9: Infografías para difusión en redes sociales para SENACE}

\section{(Twitter)}

Senace @SenacePeru.8 may.

senace Ejerce tu derecho de participar en los talleres informativos y las audiencias que dan la oportunidad de absolver todas las inquietudes relacionadas con

el Estudio de Impacto Ambiental (EIA-d). \#EIPerúPrimero

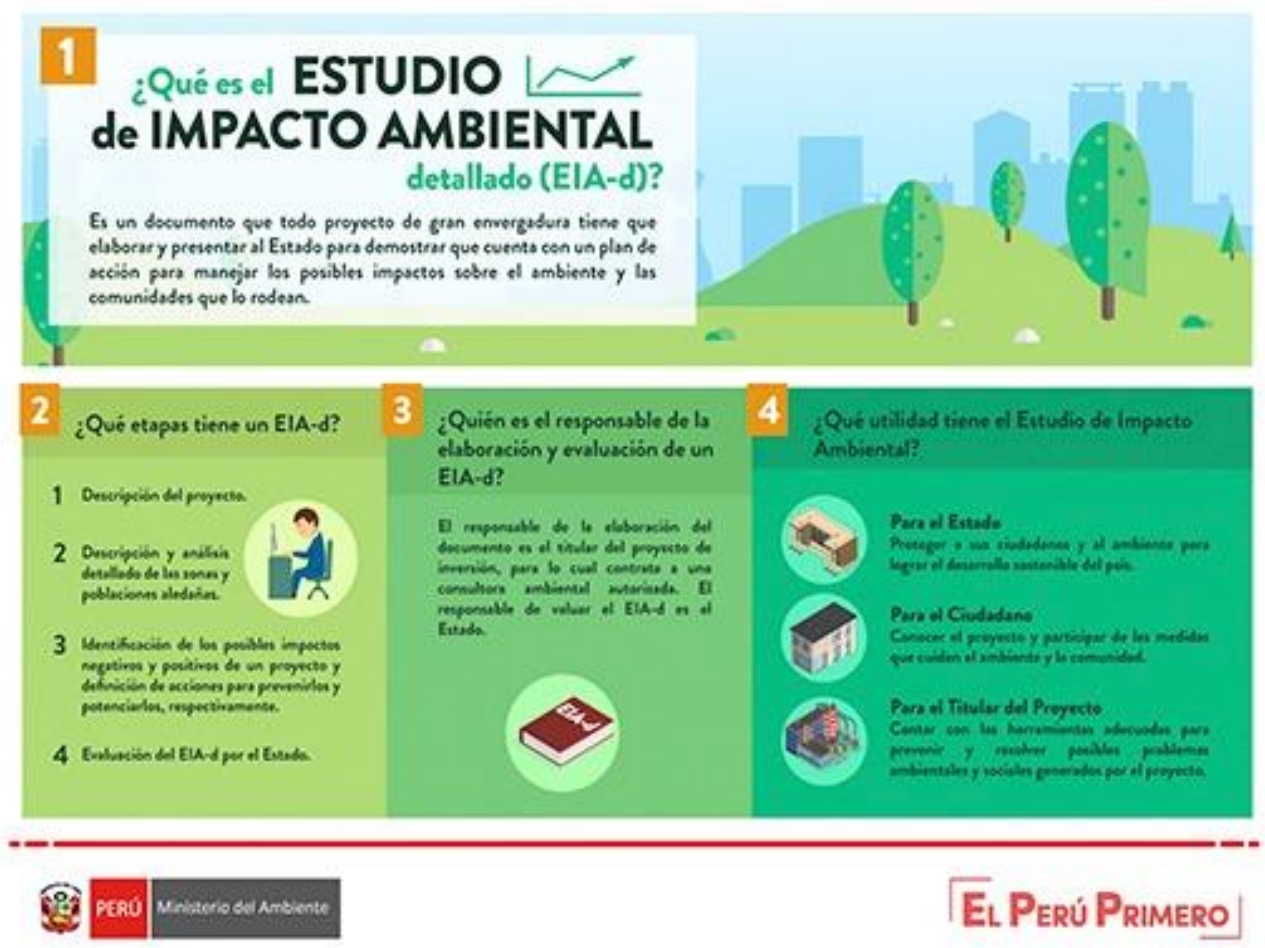




\section{Anexo 10: Guión para la producción de Video Testimonial sobre Participación Ciudadana para la certificación ambiental}

\section{GUIÓN DE VIDEO:}

La participación y aportes ciudadanos en la certificación ambiental

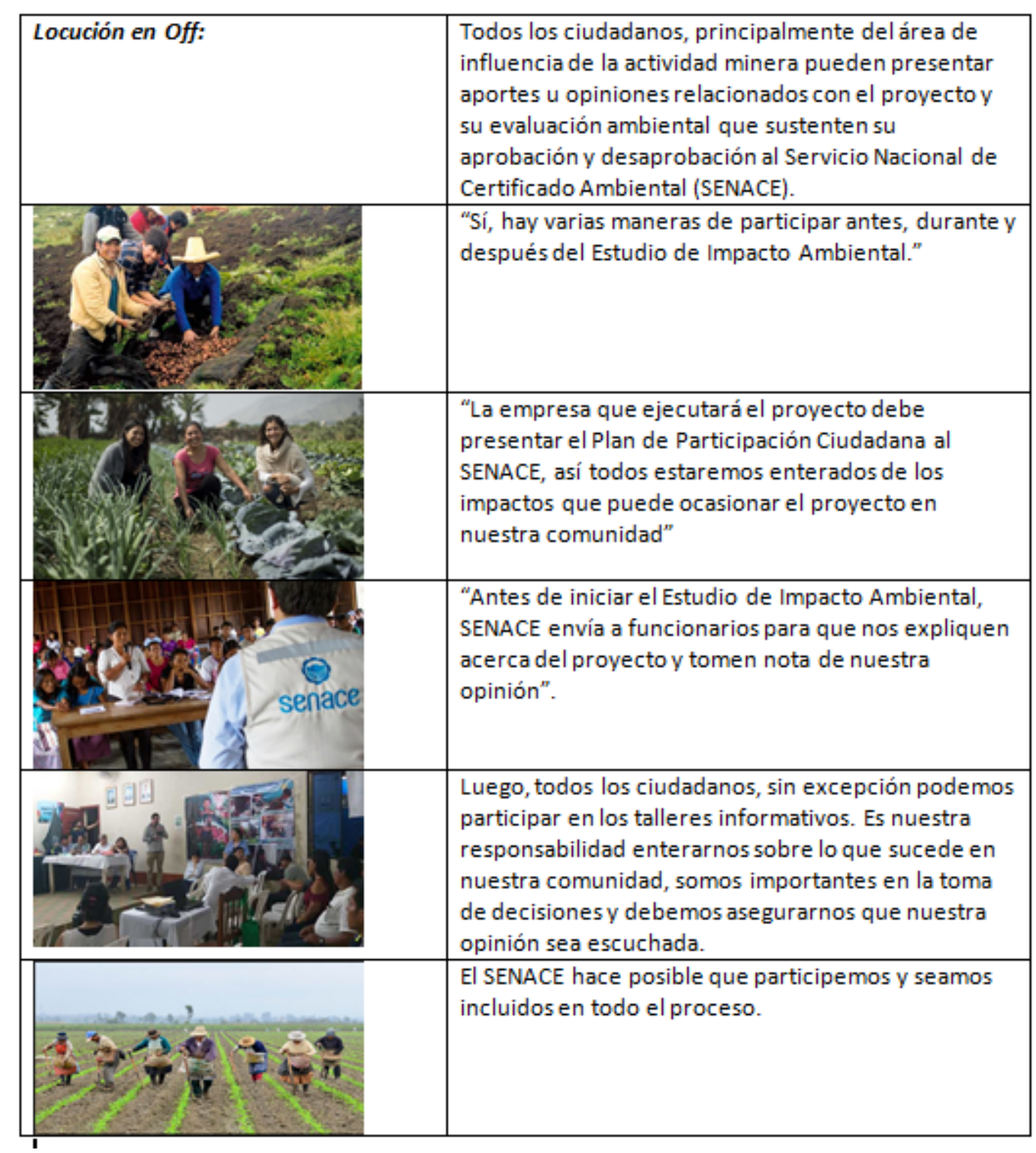




\section{Anexo 11: Aplicación móvil del Mapa de Conflictos}

\begin{tabular}{|l|l|l|}
\hline $\begin{array}{l}\text { Home de la aplicación } \\
\text { desarrollado para android e } \\
\text { IOS. }\end{array}$ & $\begin{array}{l}\text { Página de selección de la } \\
\text { región para revisión de los } \\
\text { conflictos sociales }\end{array}$ & $\begin{array}{l}\text { Pantalla de selección del } \\
\text { Proyecto con el conflicto y se } \\
\text { despliega la información del } \\
\text { mismo. }\end{array}$ \\
\hline Mapa de \\
Sociales
\end{tabular}


